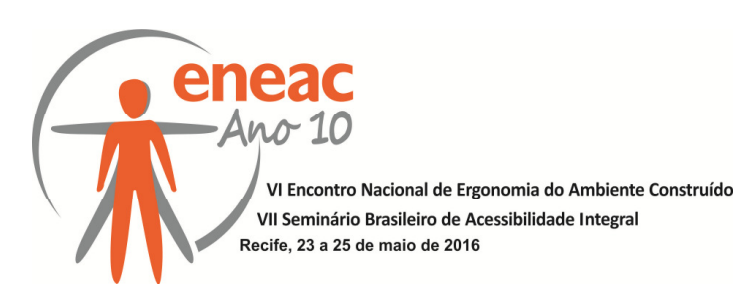

\title{
ARQUITETURA INCLUSIVA: CENTRO DE HABILITAÇÃO E REABILITAÇÃO PARA DEFICIENTES VISUAIS
}

\author{
MARTINS, Marcele Salles (1); \\ SILVEIRA, Katiane da (2); \\ ROMANINI, Anicoli (3); \\ BERNARDES, Marina (4); \\ LANTELME, Elvira (5);
}

(1) Complexo de Ensino Superior Meridional - IMED, Mestre

e-mail:marcelemartins@imed.edu.br

(2) Complexo de Ensino Superior Meridional - IMED, Arquiteta e Urbanista

e-mail:katianedasilveira@gmail.com

(3) Complexo de Ensino Superior Meridional - IMED, Mestre

e-mail: anicoli@imed.edu.br

(4) Complexo de Ensino Superior Meridional - IMED, Arquiteta e Urbanista

e-mail: marinabernardespf@hotmail.com

(5) Complexo de Ensino Superior Meridional - IMED, Doutor

e-mail:elvira.lantelme@imed.edu.br

\section{RESUMO}

O presente artigo visa apresentar aspectos pertinentes acerca da inclusão de deficientes visuais. A falta de atenção à orientação, mobilidade, autonomia e integração de deficientes visuais na sociedade constitui-se como um problema que carece de novas soluções. A arquitetura se mostra como uma possível alternativa ao desenvolver edificações que apresentam formas de atender às necessidades destas pessoas. Deste modo, se propõe um projeto arquitetônico de um centro de habilitação e reabilitação para deficientes visuais, pautado nas normativas de acessibilidade universal, arquitetura inclusiva e sustentável, promovendo espaços que possam desfrutar de uma melhor qualidade de vida.

Palavras chave: deficiência visual; arquitetura inclusiva; integração social; acessibilidade.

\section{ABSTRACT}

The aim of the present relevant aspects of social inclusion of visual impaired. The lack of attention to guiding, mobility, autonomy, and social integration of the visual impaired is a problem that needs new solutions. Architecture is a possible way to help solving this problems, through buildings that can meet their needs. Inasmuch as we propose a architectonical project of a habilitation and rehabilitation center to visual paired, based on universal accessibility norms, inclusive and sustainable architecture, promoting places where they may have a better life quality.

Keywords: visual impairness, inclusive architecture, social integration; accessibility; 


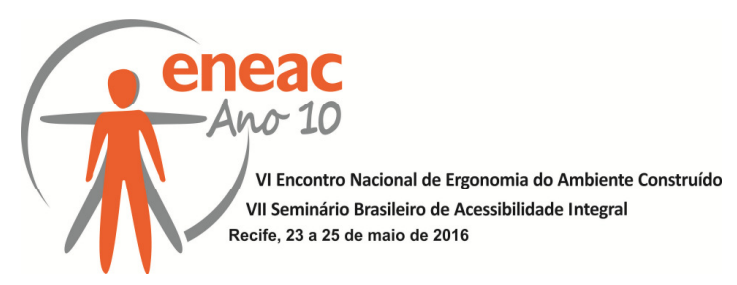

\section{INTRODUÇÃO}

O princípio da arquitetura inclusiva teve seu início diretamente ligado à Segunda Guerra Mundial, onde veteranos de guerra, mutilados, não conseguiam exercer mais funções do dia-a-dia, de modo que ficaram evidentes as barreiras arquitetônicas e os desconfortos das edificações, mostrando que as construções visavam apenas o visual arquitetônico e não as necessidades pessoais. Após o fim da Segunda Guerra, surge à primeira padronização de acessibilidade nos Estados Unidos, cuja evolução derivou o conceito de Design Universal, ou seja, produtos e ambientes que possam ser usados por todas as pessoas.

No Brasil, a arquitetura inclusiva chegou apenas na década de 1980, onde ocorreram transformações nas legislações e normas técnicas. Atualmente, a acessibilidade está presente em diversos locais como: vias públicas, áreas de convívio pessoal e social, transportes coletivos, mobiliários urbanos e em edificações públicas. Assim, pouco a pouco, uma rede articulada e acessível começa a ser delineada.

Dados fornecidos segundo as estatísticas do Censo Demográfico de 2010 (IBGE), demonstra que aproximadamente 46 milhões de brasileiros, ou seja, cerca de $24 \%$ da população, declaram-se com algum tipo de deficiência (mental, motora, visual e auditiva). Esse dado inclui também as pessoas que se declaram incapazes de ouvir, enxergar e andar (FGV, 2010). Destes, de acordo com o estudo realizado pelo IBGE, há 11,8 milhões de brasileiros com deficiência visual, dos quais cerca de 160 mil possuem incapacidade total de enxergar. A maioria das pessoas com deficiência no Brasil está localizada na área urbana. Segundo pesquisas, eles têm até três anos de escolaridade, são mulheres e quase a metade deles (48\%) ocupa a posição de chefe de família.

Esses dados constatam a baixa escolaridade das pessoas com deficiência que, como consequência sofrem a exclusão dos processos e serviços fornecidos pelos sistemas públicos e ou mercado de trabalho. Entretanto, nos últimos anos a sociedade vem passando por importantes transformações no campo conceitual. Fato este que vem sendo visualizado nas políticas voltadas para as pessoas com deficiência.

Tendo em vista estas necessidades, a arquitetura inclusiva parte do conceito de inclusão social, procurando auxiliar pessoas com necessidades especiais, apresentando os benefícios que estas proporcionam, tornando o portador de necessidades especiais independente tanto nas tarefas do dia-a-dia quanto na locomoção, buscando assim melhoria na qualidade de vida.

Considera-se Pessoa Portadora de Deficiência (PPD) aquela que apresenta, em caráter permanente, perdas ou reduções de sua estrutura, ou função anatômica, fisiológica, psicológica ou mental, que gerem incapacidade para certas atividades, dentro do padrão considerado normal para o ser humano (IBC, 2012). Além disso é de extrema importância entender e compreender a natureza desses problemas fisiológicos que atingem os indivíduos, deve-se entender suas dificuldades e problemas para assim tornar essas pessoas cada dia mais inclusas em qualquer forma seja cultural, social e ambiental.

A condição em que se encontram os deficientes visuais, atualmente, é um fator de grande preocupação, visto a falta de atenção dedicada a estas pessoas. Além disso, futuramente, esta situação está propensa a piorar, pois os riscos de deficiências visuais se consolidam na medida em que a população idosa aumenta em índices demográficos e as doenças se alastram com maior facilidade.

Neste ínterim, a arquitetura é proposta como uma maneira de solucionar este dilema atual, proporcionando perspectivas positivas através da adoção de medidas concretas, a partir do desenvolvimento de centros de reabilitação para deficientes visuais, empreendendo fatores técnicos e funcionais, que atendam ao objetivo de emancipar estas pessoas, oferecendo um programa de necessidades adaptado à superação de muitos obstáculos que os impedem de 


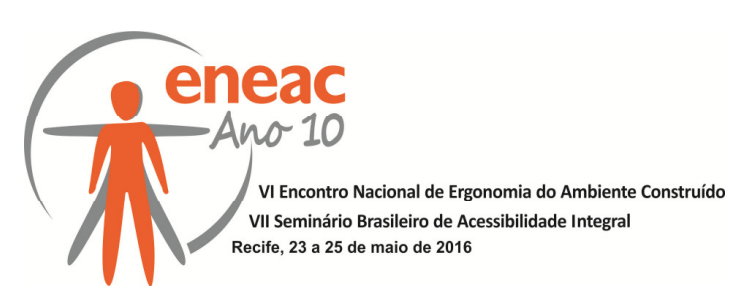

participar da comunidade, receber uma educação qualificada, obter um emprego digno e também abolir a discriminação.

Dessa forma, o projeto arquitetônico também possui um caráter social, ao empregar medidas que busquem solucionar as deficiências existentes no atendimento destas pessoas, promovendo reabilitação, serviços de apoio, políticas para criação de entornos adaptados, tendo como base a aplicação de normas e legislações que ditem benefícios para a deficiência visual.

Frente ao exposto, o presente artigo tem como objetivo apresentar um projeto para a construção de um centro de habilitação e reabilitação inclusivo e sustentável, destinado principalmente a pessoas com deficiência visual, seguindo os princípios da Arquitetura Inclusiva e Sustentável. Este objetivo se fundamenta na demanda de programas sociais que proporcionem a inclusão social para pessoas portadoras de necessidades especiais, que garantam autonomia e a inserção efetiva e consciente na sociedade.

\section{CENTRO ESPECIAL}

Mesmo antes da invenção do Braille, já havia sido criada a primeira escola para educação de cegos, na França, o Instituto Real dos Jovens Cegos, por Valentin Hauy, que ensinava através de um método tátil de leitura. Após a importante conquista na história da deficiência visual, o Braille, começaram a surgir diversas escolas, na Europa. Além do ensino em si, muitos procuravam abordar o aspecto psicológico da incapacidade visual, entre as quais pode-se destacar a St, Dunstan, na Inglaterra.

A partir de então, as escolas especiais e associações de cegos se difundiram por todo o mundo. No Brasil, foi criada a primeira instituição, em 1854, no Rio de Janeiro, o Imperial Instituto dos Meninos Cegos, existente até hoje, porém com outro nome, Instituto Benjamin Constant.

Também houve a criação de turmas especiais para cegos dentro de escolas públicas, sendo a primeira delas fundada nos Estados Unidos, no ano de 1900. Com o mesmo conceito, a Perkins School, de Boston, graduou a aluna Helen Keller, cega, surda e muda, que conseguiu um feito histórico, ao se formar no curso superior e, mais tarde, publicar diversos livros a respeito da educação para cegos.

Com isso, as publicações de materiais didáticos em Braille, sobre a deficiência visual, tomaram força, recebendo apoio da Organização das Nações Unidas para a Educação, a Ciência e a Cultura (UNESCO).

Porém esta medida "especial" fornecia ensino e capacitação, mas não inclusão e integração social, ao contrário, desde crianças, os deficientes visuais eram excluídos, obrigados a procurar instituições especiais se sua intenção fosse receber uma instrução educativa. As pessoas que não apresentavam cegueira, mas dificuldades de leitura e escrita ocasionadas pela deficiência visual, ainda assim, deveriam frequentar classes especiais, pois não havia método de ensino nas escolas.

Mais tarde, começou a ser aplicado o método inclusivo, que visava adotar medidas pedagógicas modernas dentro das turmas e escolas, para inserção e deficientes visuais no sistema escolar comum, desde os primeiros anos até a graduação superior, combatendo a discriminação existente. Dessa forma, cegos e outros deficientes podem se sentir incluídos e parte da sociedade, conquistando independência, autonomia e autoestima.

Aos poucos, além de centros educativos, começaram a ser criados centros de habilitação e reabilitação, que ofereciam serviços de capacitação motora e psicológica, esportes, lazer, diversão e diversas atividades para os deficientes visuais. 


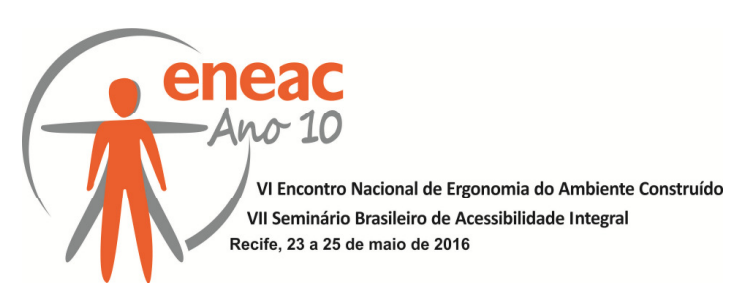

Atualmente, o Braille apresenta um importante impulso na educação e capacitação de cegos. Da mesma forma, a informática assumiu uma forte atuação, pois oferece programas adaptados que garantem a acessibilidade às diversas técnicas de informação.

\section{PROCEDIMENTO METODOLÓGICO}

A metodologia a ser empregada nesse projeto está estruturada na realização de estudo de caso. O estudo de caso é uma pesquisa empírica que investiga um fenômeno contemporâneo dentro de seu contexto real, em que as fronteiras entre o fenômeno e o contexto não são claramente evidentes em que múltiplas fontes de evidência são utilizadas (YIN, 2005). Assim a essência de um estudo de caso ou a tendência de todos os tipos de estudo de caso é que tentam esclarecer uma decisão ou conjunto de decisões: por que foram tomadas? Como foram implementadas? E quais os resultados alcançados? Dessa maneira, esse tipo de estratégia passa a ser adequado a uma pesquisa em que procura aplicá-la num projeto.

A partir dos estudos de caso realizados e de visita in loco a Associação dos Deficientes Visuais foi fundamentado o programa de necessidades, distribuído em setores que conformam os serviços oferecidos no centro de habilitação e reabilitação que se encontra alinhado às definições da Norma de Acessibilidade.

\section{CENTRO DE HABILITAÇÃO E REABILITAÇÃO PARA DEFICIENTES VISUAIS}

A abordagem da deficiência visual exige o conhecimento de diversos conceitos que devem ser considerados em qualquer estudo ou objetivo que pretenda proporcionar atendimento a estas pessoas.

Primeiramente, é importante definir deficiência como qualquer tipo de comprometimento que interfira na integridade física ou mental de uma pessoa, desde mobilidade, compreensão, orientação espacial ou convivência na sociedade (GODOY et al., 2005). Por conseguinte, o conceito de cidadania, refere-se à asseguridade dos direitos de todas as pessoas, bem como o cumprimento dos deveres de cada um, principalmente o dever de respeitar o direito do outro. Como exemplo específico ao tema, pode-se citar o direito do cidadão deficiente de receber assistência social, através de habilitação, reabilitação e promoção de sua integração na vida comunitária (GODOY et al., 2005).

Um Centro de habilitação e reabilitação para deficientes visuais deve, acima de tudo, conceder segurança e confiança aos seus usuários, para que os espaços sejam bem aproveitados e as atividades proporcionem os melhores resultados possíveis. Além disso, conforme cita o arquiteto Chris Downey (2011), conhecido pelos seus projetos para cegos, "é essencial que a orientação das instalações seja legível e lógica, para que os usuários possam movimentar-se de maneira fácil e independente. Incorporar elementos que propiciem um espaço mais claro e compreensível ajudará muito aqueles que podem enxergar".

Outros recursos também devem fazer parte da proposta arquitetônica, em função dos mesmos objetivos, como por exemplo, pavimentações, equipamentos, elementos sensoriais e, inclusive, um sistema tecnológico de automação, que permita um melhor controle das operações que funcionam na edificação. Os acessos, por exemplo, devem apresentar certa hierarquia para demarcá-los, através de diferenciação de materiais ou elementos. Esta técnica, além de importante e necessária, cria um diferencial funcional e arquitetônico (DOWNEY, 2011). 


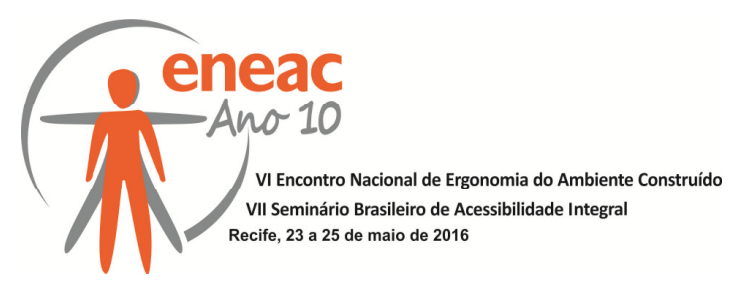

Para que um projeto se torne inclusivo, é necessário que as intervenções ocorram desde à rua em frente ao estabelecimento, por exemplo com a inserção de rampas de acesso, piso tátil e sinalizações. Desta forma, o projeto propôs diversas alterações no espaço público, para que possibilitasse igualdade no acesso à todos os usuários, além das intervenções mínimas exigidas foi implantada a faixa de pedestre elevada e requalificação do passeio público com a utilização de arborização junto ao lote.

O projeto buscou uma integração com o meio externo, promovendo adaptações no entorno próximo, quanto à infraestrutura urbana, garantindo condições igualitárias de acesso aos cidadãos, em prol da autonomia pessoal e cívica dos deficientes visuais. Além disso, aplica também o conceito estético, externamente na escolha dos materiais, empregando cores fortes e contrastantes, e texturas que possibilitem uma impactante comunicação visual e sensorial para aqueles que apresentam um mínimo de visão. Internamente, as cores e os elementos servem como sinalizações de orientação, de modo a contribuírem para a funcionalidade da edificação.

Em todo o projeto foi utilizado o piso tátil, pois é fundamental para direcionar as pessoas com deficiência visual, a sua locomoção e orientação com segurança depende da inserção do piso nas áreas públicas e calçamentos. Além disso, existe o piso tátil de alerta, é utilizado para informar situações de perigo e obstáculos nos cruzamentos, desníveis e escadas, indicando a mudança das direções nos percursos. O piso deve ser confortável, para que a pessoa possa, tanto utilizá-lo com bengala, quanto apenas caminhando.

A implantação foi setorizada permitindo que os espaços internos obtivessem melhor aproveitamento de luz natural e ventilação, sendo dividida em dois blocos. O bloco $A$ destinado ao lazer, para prática de esportes e piscina. E o bloco principal $B$ que abriga todas as atividades propostas no Centro. A área externa abriga um jardim sensorial (C), playground (D) pista para treinamento de obstáculos (E), e horta (F). (Figura 1).

Figura 1 - Implantação do Centro

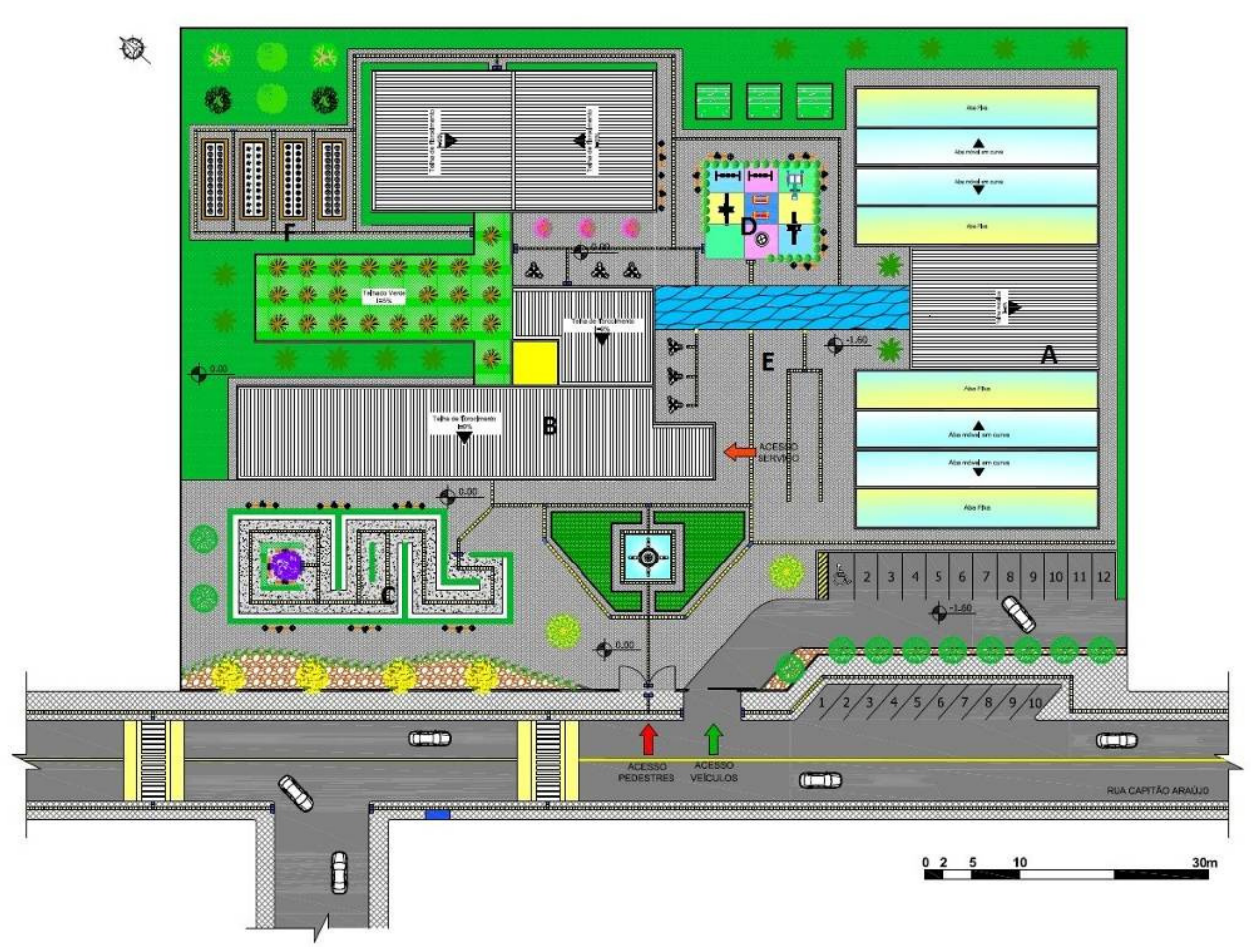

Fonte: Autores, 2015. 


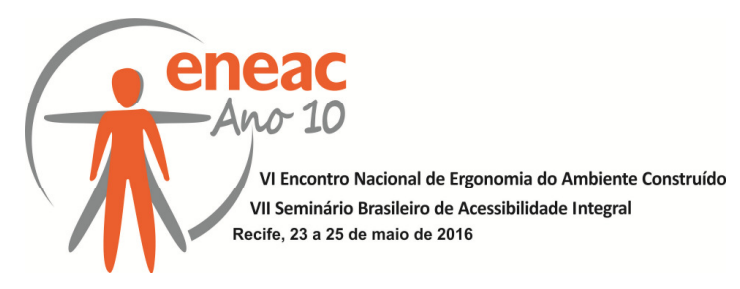

De posse das informações abordadas na evolução da deficiência visual e da recorrente situação socioeconômica e sociocultural atual, o projeto objetiva retomar estas questões, ao propor uma edificação com caráter arquitetônico funcional, que considere os limites e destaque as possibilidades das pessoas portadoras de deficiência visual, com a proposição de atividades que assegurem, efetivamente, os direitos deste segmento da população, possibilitem a sensibilização, conscientização e participação da sociedade, e, ao mesmo tempo, chamem atenção e orientem a gestão pública para que a criação de espaços como este seja crescente. A instituição deve oferecer um centro de referência e excelência na disponibilização de serviços socioassistenciais que atendam os deficientes visuais, apoiando seu desenvolvimento e sua efetiva participação na comunidade, na família, na escola e no mercado de trabalho.

Sendo assim, o programa de necessidades proposto buscou, além de integrar os espaços exigidos, ter o cuidado de estabelecer uma distribuição otimizada de acessos, compartimentos e circulações, desenvolvendo um Centro organizado e coerente do ponto de vista funcional e espacial. Os espaços seguiram uma setorização, proporcionando áreas privativas e sociais, para convivência.

A utilização dos compartimentos ocorre de modo variável, já que a frequência dos usuários pode ser tanto fixa, como eventual, e os serviços oferecidos não possuem horários padrões ou um cronograma de atividades a ser seguido, tudo dependendo da capacidade ou dificuldade física, psíquica e emocional do deficiente visual.

Segundo o arquiteto Chris Downey (2013), com cegueira do tipo adquirida após sua formação profissional, "o desafio de criar espaços acolhedores para deficientes visuais é que as qualidades ópticas passam a ser a última preocupação. O conceito de projeto e execução de uma boa edificação é um espaço que ofereça interação sensorial".

A edificação é flexível, com uma concepção arquitetônica totalmente adaptada ao atendimento integral das necessidades habilitativas e reabilitativas dos deficientes visuais e o funcionamento de diversas atividades, adotando sistemas tecnológicos modernos, aplicados tanto ao programa de necessidades, quanto à estrutura da edificação, criando um espaço permeável às suas expectativas e desejos, e contribuindo com a formação da cidadania. A proposta considera sua crença no potencial dos deficientes e a inexistência ou precariedade de serviços e espaços dedicados a esse objetivo, para criar um espaço de interação recreativa, educacional e sociocultural, garantindo oportunidades e promovendo uma transformação na qualidade de vida destas pessoas.

O projeto adota um conceito característico à sua função, ou seja, considerando o público a quem se propõe e as atividades oferecidas para seu integral atendimento, seu conceito é constituído por um caráter arquitetônico e social. Assim, o objetivo primário é atingir ambas as perspectivas conceituais, através do desenvolvimento de setores que proporcionem reabilitação, resgate emocional e psicológico, e integração na comunidade.

O projeto propõe um perfil diversificado de atividades, que se conformaram em um complexo arquitetônico e, principalmente, funcional, atendendo pessoas de todas as faixas etárias em integração num único espaço, totalmente conectado à realidade urbana e social, valorizando a densidade de deficientes visuais na sociedade atual, a fim de desenvolver um potencial no município e região e atuar na conscientização social.

O projeto do bloco principal conta com dois pavimentos, sendo o primeiro pavimento destinado ao setor administrativo e de serviço, tendo a rampa como elemento integrador e espaço de convivência. No pavimento térreo contempla um mini-auditório, lar experimental e um ateliê de esculturas. (Figura 2). 


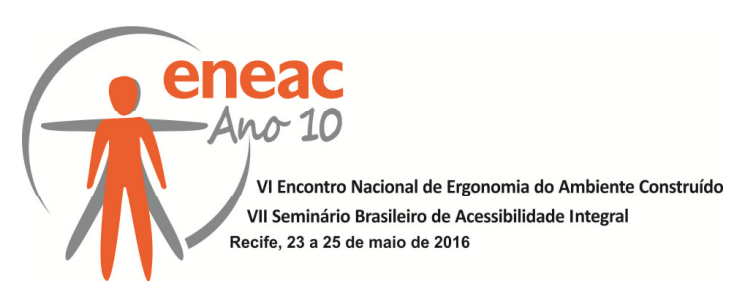

Figura 2 - Planta baixa do pavimento térreo

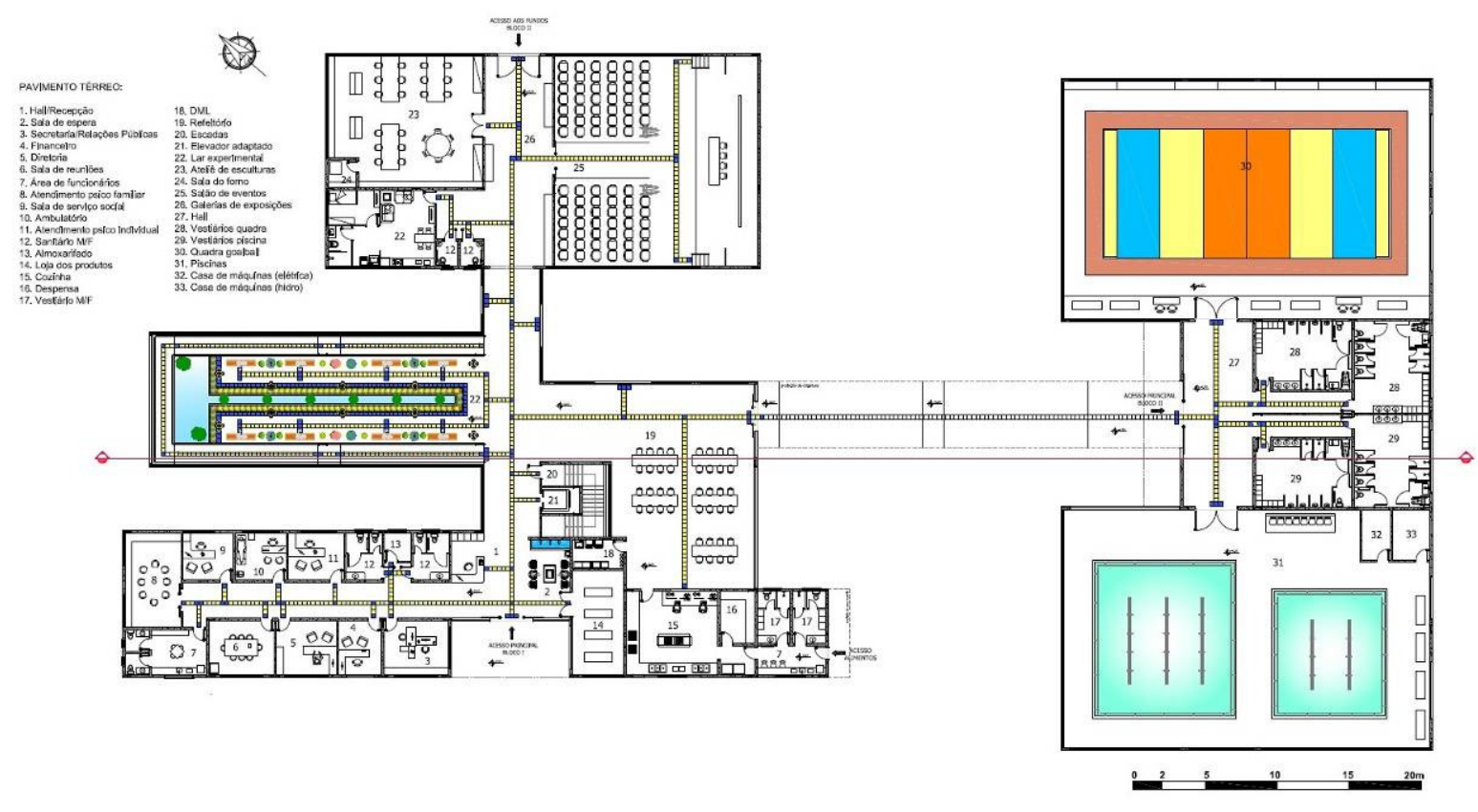

Fonte: Autores, 2015.

O primeiro pavimento possui acesso pela rampa, escada ou elevador, disposto no centro da edificação, se concentra as salas de recursos, oficina e terapia ocupacionais, reforço de aprendizagem, optometria, psicomotricidade, orientação e mobilidade, estimulação precoce, sala de música, teatro e de dança. Brinquedoteca, musicoterapia, cyber espaço, multimídia. biblioteca e biblioteca infantil.(Figura 3).

Figura 3 - Planta baixa do primeiro pavimento

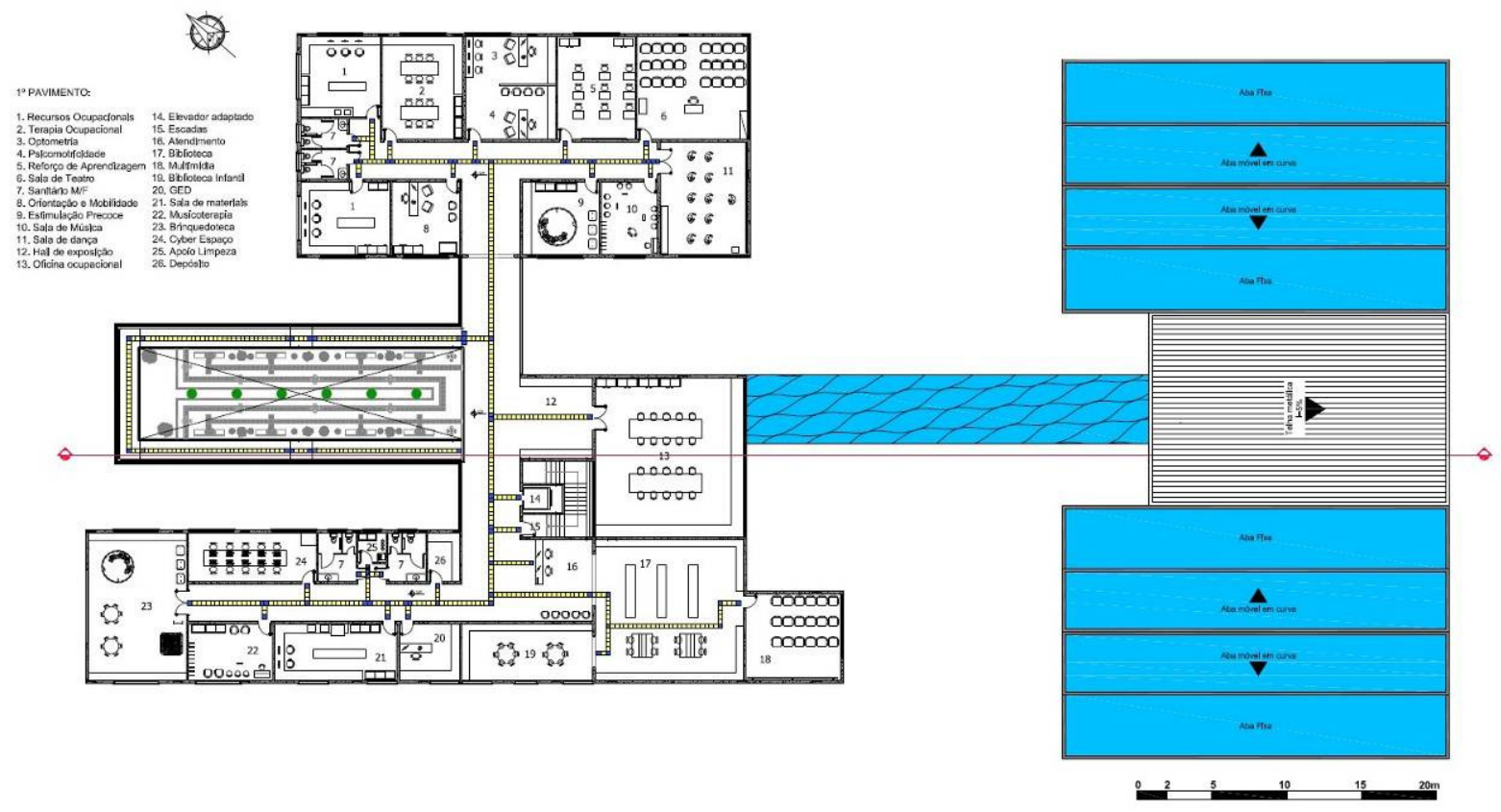

Fonte: Autores, 2015. 


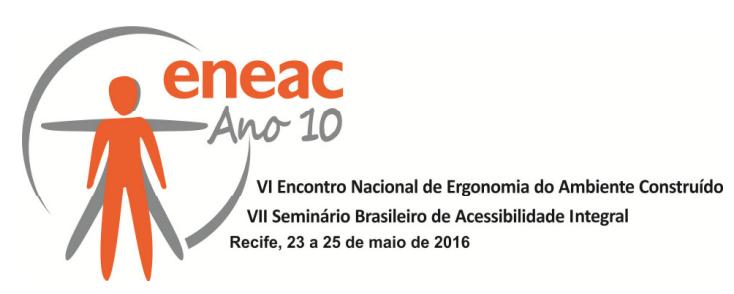

Os espaços são concebidos segundo a linguagem do desenho universal, visando a melhor utilização possível por pessoas com deficiência visual, num sentido de integração e bemestar, minimizando quaisquer complexidades da vida cotidiana e maximizando as capacidades dos deficientes visuais, provendo espaços adequadamente assistidos e oferecendo serviços efetivos que acompanhem as expectativas e interesses dos usuários da instituição. (Figura 4).

Figura 4 - Espaço de Convivência

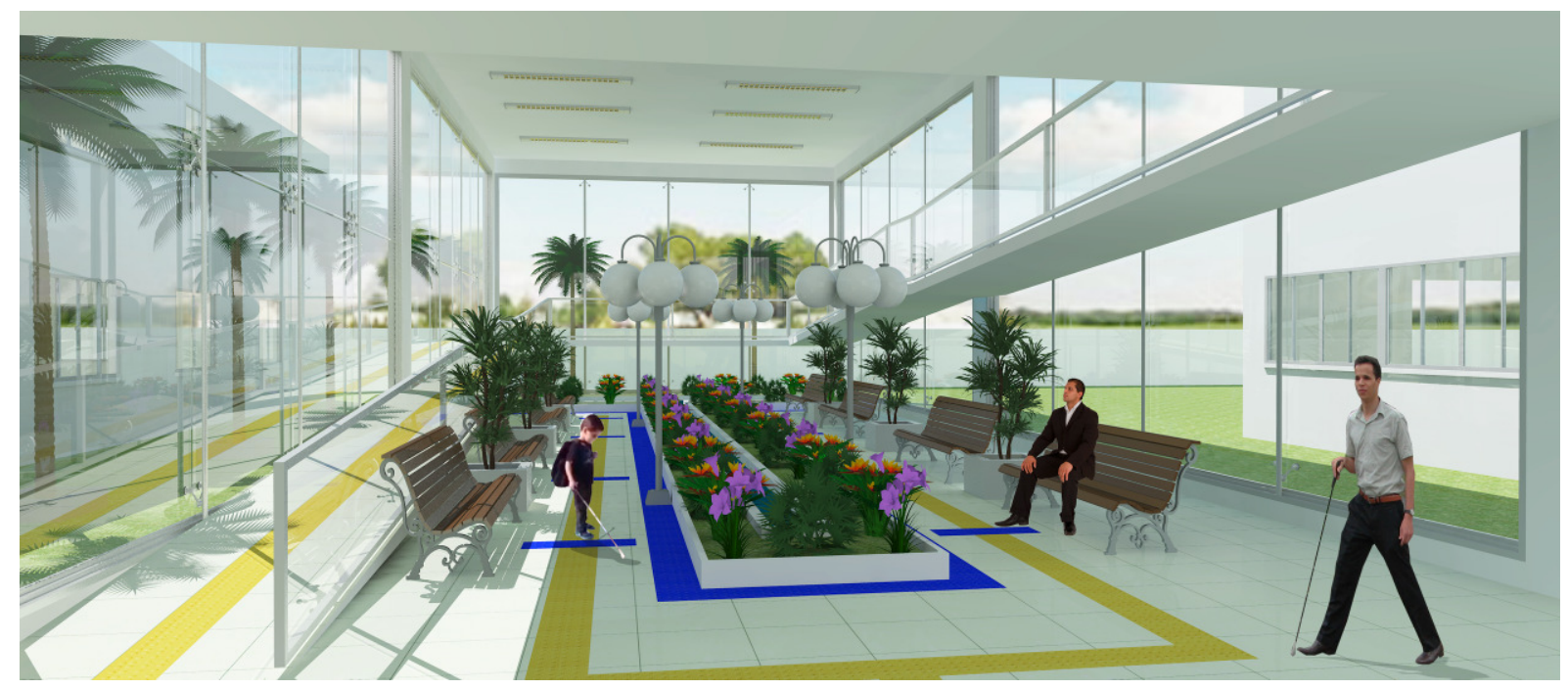

Fonte: Autores, 2015.

\section{CONCLUSÕES}

A visão que impulsiona este projeto é a de um mundo inclusivo, em que todas as pessoas, especialmente estes discriminados, cognitivamente ou concretamente, pela sociedade, possam desfrutar de uma vida de qualidade, com saúde, segurança e dignidade, além de contribuir com a conscientização populacional.

Considerando o estudo realizado, é possível evidenciar que o atendimento insuficiente da deficiência visual é um fator que se propagou durante muitos anos e, até hoje, ainda é causa de exclusão social, visto que estas pessoas não recebem a reabilitação necessária ao desenvolvimento de suas capacidades e sua integração na sociedade. Esta realidade atual possui vários aspectos responsáveis, como o governo, que deve oferecer condições de vida digna para toda a população, nesse caso, instituições que promovam a autonomia e capacitação educacional, profissional, recreativa e social dos deficientes visuais, e também a sociedade que deve se conscientizar e colaborar para esta ação.

Porém, a arquitetura se mostra como uma eficiente solução, pois, aliada à responsabilidade social, desenvolve edificações que apresentam medidas concretas ao atendimento destas pessoas, através da visão de um mundo inclusivo, propondo espaços que possibilitem saúde física e psicológica, educação, autonomia, integração e reabilitação como um todo.

A arquitetura apresenta-se como um diferencial ao oferecer técnicas formais, funcionais e estéticas que desenvolvam os aspectos objetivos e cognitivos dos usuários da instituição. A realização dos estudos de caso e a pesquisa bibliográfica influenciaram de forma positiva na composição do projeto, pois demonstraram algumas soluções arquitetônicas eficientes ou passíveis de melhorias, que puderam ser analisadas e aplicadas no Centro. 


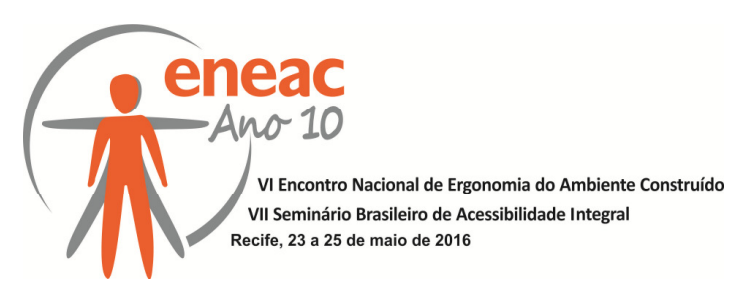

\section{REFERÊNCIAS BIBLIOGRÁFICAS}

Associação Brasileira de Normas Técnicas - ABNT. NBR 9050: Acessibilidade a edificações, mobiliário, espaços e equipamentos urbanos. Comitê Brasileiro de Acessibilidade: ABNT, 2004.

Instituto Benjamin Constant - IBC. Os conceitos de deficiência: As diversas definições. Disponível em: <http://www.ibc.gov.br/?itemid=396>. Acesso em 05 mai. 2012.

Instituto Brasileiro de Geografia e Estatística - IBGE. Censo Demográfico 2010 - Características gerais da população, religião e pessoas com deficiência. Disponível em: $<$ http://www.ibge.gov.br/home/presidencia/noticias/noticia_impressao.php?id_noticia=2170

Deficientes>. Acesso em 12 out. 2012.

Mello, R. Instituto Brasileiro de Desenvolvimento da Arquitetura - IBDA Arquitetura Inclusiva - Uma nova cultura. Disponível em: <http://www.forumdaconstrucao.com.br/conteudo.php?a=32\&Cod=1013>. Acesso em 12 out. 2012.

YIN, R.K. Estudo de caso: planejamento e métodos. 3a ed. Porto Alegre: Bookman, 2005. 